\title{
BM] Global Health System-wide analysis of health financing equity in Cambodia: a study protocol
}

\author{
Virginia Wiseman, ${ }^{1,2}$ Augustine Asante, ${ }^{1}$ Por $\mathrm{Ir},{ }^{3}$ Supon Limwattananon, ${ }^{4,5}$ \\ Bart Jacobs, ${ }^{6}$ Marco Liverani, ${ }^{2}$ Andrew Hayen, ${ }^{7}$ Stephen Jan $^{8}$
}

To cite: Wiseman $\mathrm{V}$, Asante A, Ir P, et al. Systemwide analysis of health financing equity in Cambodia: a study protocol. BMJ Global Health 2017;2:e00153. doi:10.1136/bmjgh-2016000153

Received 10 August 2016 Revised 17 November 2016 Accepted 22 November 2016

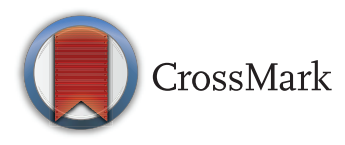

For numbered affiliations see end of article.

Correspondence to Dr Virginia Wiseman; Virginia.wiseman@Ishtm.ac.uk

\section{ABSTRACT}

Background: To assess progress towards universal health coverage, countries like Cambodia require evidence on equity in the financing and distribution of healthcare benefits. This evidence must be based on a system-wide perspective that recognises the complex roles played by the public and private sectors in many contemporary healthcare systems.

Objective: To undertake a system-wide assessment of who pays and who benefits from healthcare in Cambodia and to understand the factors influencing this.

Methods: Financing and benefit incidence analysis will be used to calculate the financing burden and distribution of healthcare benefits across socioeconomic groups. Data on healthcare usage, living standards and self-assessed health status will be derived from a cross-sectional household survey designed for this study involving a random sample of 5000 households. This will be supplemented by secondary data from the Cambodian National Health Accounts 2014 and the Cambodian Socioeconomic Survey (CSES) 2014. We will also collect qualitative data through focus group discussions and in-depth interviews to inform the interpretation of the quantitative analyses.

Potential impact: This study will produce previously unavailable information on who pays for, and who benefits from, health services across the entire health system of Cambodia. This evidence comes at a critical juncture in healthcare reform in South-East Asia with so many countries seeking guidance on the equity impact of their current financing arrangements that include a complex mix of public and private providers.

\section{INTRODUCTION}

Universal health coverage (UHC), which implies that all people have access to needed services without the risk of financial ruin, has become a major goal for health reform in many countries. ${ }^{1-3}$ The World Health Report 2010 on universal coverage of healthcare, and the associated declaration of the World Health Assembly, urged member states to 'aim for affordable universal coverage and access for all citizens on the basis of equity and solidarity'. ${ }^{5}$ The way health systems are financed is a critical determinant for reaching universal coverage. ${ }^{2}$ A health financing system is often divided conceptually into three inter-related functions: revenue generation, pooling of resources and purchasing of interventions. ${ }^{6}$ Revenue generation is concerned with the raising of funds either directly from users of healthcare or indirectly through governments or donors. Pooling is the accumulation and management of revenues in ways that ensure that the risk of paying for healthcare is borne by all the members of the pool and not by each contributor individually. Purchasing is the process of allocating funds to providers of healthcare. ${ }^{6}$ Equity in health financing refers to the distribution of the burden of paying for healthcare according to the ability to pay and the benefits from health spending on the basis of need. $^{2}$

Many low-income and middle-income countries (LMICs), including Cambodia, are currently seeking to reform their health financing systems so they can move quickly to UHC and to sustain it once it has been achieved. $^{5-8}$ Cambodia's Second Health Sector Strategic Plan 2008-2015 sought to put in place financing reforms designed 'to enhance sustainable development of the health sector for better health and well-being of all Cambodians, especially of the poor, women and children, thereby contributing to poverty alleviation and socioeconomic development'. ${ }^{9}$ These reforms are being pursued against a backdrop of widespread poverty. ${ }^{10}$ Cambodia is one of the poorest countries in the Asia Pacific region with about 2 out of every 10 Cambodians living below the national poverty line; and rates of healthcare use are among the lowest in the region. ${ }^{11}$ The country is characterised by a highly fragmented health system with a dominant and 
growing private sector. ${ }^{11}$ While government expenditure on health has recently increased, it remains low at just $1.4 \%$ of gross domestic product (GDP) and total health expenditure is $7 \%$ of GDP. ${ }^{12}$ In contrast, out-of-pocket health expenditure by households is high with such spending as a proportion of household budget at around $5 \%$ and as a proportion of total health expenditure at $6 \%$, some of the highest rates in Asia. ${ }^{13} 14$ These expenses are mainly accrued in the private-for-profit sector, which is the main source of healthcare. Despite the growing scale and importance of the private or nonstate sector across most LMICs, few attempts have been made to integrate public and private sectors into assessments of equity in healthcare payment and service use. ${ }^{2}$

Cambodia is currently exploring new financing mechanisms designed to promote access to effective and affordable healthcare for its population, especially the poor. ${ }^{10} 12$ These include internal contracting and a government midwifery incentive scheme to boost facility deliveries, voluntary health insurance schemes targeting the informal sector as well as a range of voucher schemes designed to increase the uptake of reproductive and safe motherhood services by poor rural communities. ${ }^{15-18}$ From a financing perspective, Cambodia is perhaps best known for its innovative Health Equity Funds (HEF), a third party payer mechanism that reimburses public facilities for health services rendered to the poor. Although the initiative has now been expanded to cover $\sim 3.2$ million poor, results until now have been mixed. ${ }^{14}{ }^{19-21}$ The 2014 Demographic and Health Survey found that only $9.3 \%$ of men and $13.1 \%$ of women in rural areas had their health services paid for by a HEF. ${ }^{14}$ Another review found that HEFs considerably reduced out-of-pocket payments for health but had no impact on care seeking and borrowing to pay for healthcare. ${ }^{21}$ The most recent review by Annear and colleagues found that more than $20 \%$ of all services measured at referral hospitals are supported by a HEF and $\sim 20 \%$ for services at health centres (HCs), leading the authors to conclude that HEF members (the poor) access services at hospitals at a greater proportion relative to their population size, and at approximately the same proportion at HCs. ${ }^{19}$ Evaluations of individual financing schemes such as HEFs are valuable but do not replace the need for evidence on the equity of healthcare spending and service use for the health system as a whole. ${ }^{2}$

As Cambodia forges its path to universal coverage and while debate grows on the relative merits of different financing schemes, it is crucial that evidence on equity in health systems financing is made available. This project will undertake a 'whole-of-system' assessment of who pays and who benefits from healthcare in Cambodia that incorporates Cambodia's thriving private sector.

\section{Research objectives and questions}

The primary objective of this 3-year study (March 2015 to March 2018) is to evaluate equity in healthcare payment and service use in Cambodia to support progress towards UHC. Lessons from this study will be relevant to a number of countries in the region that have similar health financing systems such as Vietnam, Laos and Myanmar. Specific study questions include:

1. How is the burden of healthcare payments distributed across socioeconomic groups in Cambodia?

2. How are the benefits from the health financing system (measured in terms of healthcare use) distributed across socioeconomic groups and according to level of need?

3. What are the complex range of determinants of healthcare usage and household spending on health services in Cambodia?

\section{METHODS}

\section{Theoretical framework}

A conceptual framework can be useful in understanding how a health financing system is currently organised and for assessing the equity impact of financing reforms. ${ }^{7} 2223$

Frameworks like the one shown in figure 1 have been proposed for analysing the performance of health financing systems and depict health financing in terms of the broad functions of collecting revenue, pooling resources, and purchasing goods and services. ${ }^{23}$ The framework shows that these functions often involve complex interactions among a range of players in the health sector. This conceptual framework is intended as a starting point and it is our aim to use this as a basis for developing a more insightful framework for the Cambodia setting that reflects the multidimensional array of institutional and organisational arrangements in the local country context. The framework will also enable a more precise characterisation of public and private roles in healthcare financing, something widely acknowledged but, as previously mentioned, not well understood. $^{2}$

\section{Study setting}

This study assesses equity in healthcare use and spending across the entire healthcare system of Cambodia which serves an estimated population of 15.8 million. ${ }^{24}$ Around $80 \%$ of the population live in rural areas, practising traditional wet rice cultivation and other forms of agriculture, often at a subsistence level. ${ }^{25}$ The Khmer make up $90 \%$ of the population while the remaining $10 \%$ includes Vietnamese, Chinese, Cham-Malay and other diverse ethnic minority groups. ${ }^{25}$ While the Ministry of Health has overall responsibility for the health sector, the Cambodian health market has a wide variety of public and private healthcare providers. ${ }^{12} 26$ The main provider of primary healthcare in Cambodia is the private sector with only one in three patients visiting the public sector for outpatient care. ${ }^{26}$ Two-thirds of public health staff also work privately. ${ }^{12}$ Non-governmental organisation health facilities and charitable hospitals also provide services. Qualified 


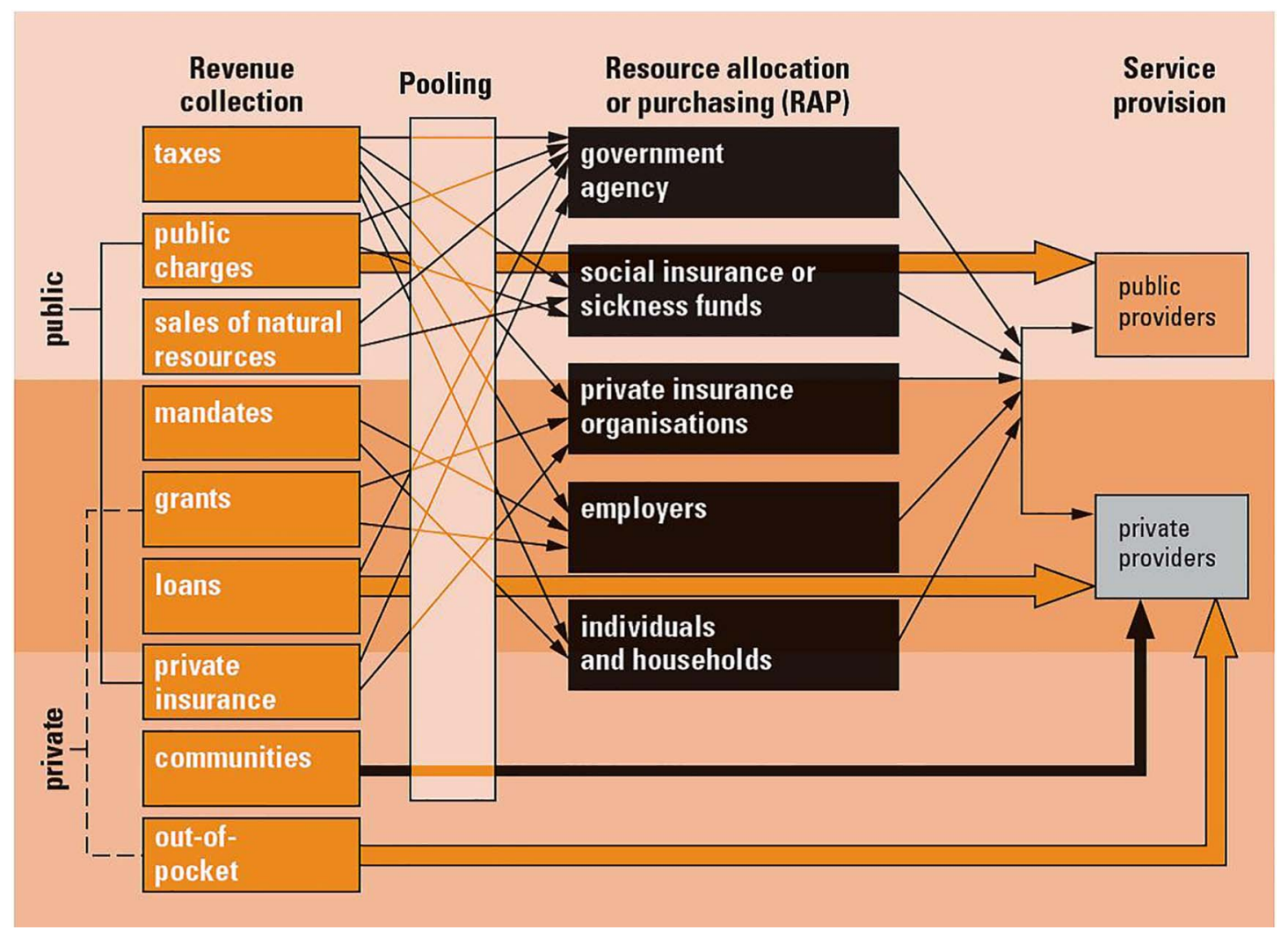

Figure 1 Flow chart of the study selection process.

private providers and pharmacies are most common in urban areas. Non-medical health providers such as traditional healers and drug peddlers are an important source of care and can be found throughout the country selling drugs from shops, markets or through home visits. ${ }^{12}$ Government funding supports most of the health infrastructure and staffing in the community, and delivers a subsidised, standard package of preventive, primary and curative care. ${ }^{12}$ Revenues at government facilities are supplemented by user charges introduced in 1996, with exemptions provided to the poor. Government health services are financed from general revenues, supported by donor funding. ${ }^{12}$ Currently, there is no compulsory health insurance or social health insurance coverage.

\section{Study phases and design}

The research questions will be addressed using a mix of quantitative and qualitative methods. The quantitative methods include the analysis of secondary data from the latest national surveys and primary data from a crosssectional household survey. Qualitative methods comprise in-depth interviews and focus group discussions.

The project consists of three phases:

1. Quantitative assessment of equity in health care payment and service use;

2. Qualitative investigation of factors influencing equity in healthcare delivery and payments, paying particular attention to the role of the private sector (vis-à-vis the public sector); and

3. Integration and dissemination of findings from phases 1 and 2.

Phase 1: measuring equity in healthcare delivery and payments

This component of the study uses financing incidence analysis (FIA) and benefit incidence analysis (BIA), internationally accepted methods for the evaluation of equity in health systems financing, to measure the extent to which healthcare payments are related to ability to pay (ATP) and the use of healthcare is related to need. ${ }^{2} 27-30$

\section{Data sources and sampling}

A combination of secondary and primary data is required for the incidence analyses. For the FIA, the Cambodian National Health Accounts (NHA) 2014 ${ }^{31}$ and the Cambodian Socioeconomic Survey (CSES) $2014^{32}$ will be used to estimate the healthcare spending mix and private/household payments to health through direct and indirect taxation, out-of-pocket payments (eg, for healthcare and medication) and any insurance contributions. Tax thresholds and actual revenue from each tax source will be those reported by the Ministry of Finance. ${ }^{33}$ A key challenge of using existing national household survey data sets such as the CSES is that households may under-report their income, making it 
difficult to estimate their tax contributions. To overcome these challenges, we intend to triangulate the revenues estimated from the survey data with actual revenue estimates obtained from the appropriate national authorities. $^{28}$

For the BIA, unit cost data for the different health services will be derived from a recent hospital and $\mathrm{HC}$ costing study conducted by the Cambodian Ministry of Health. ${ }^{34}$ The BIA also requires healthcare usage data on every episode of care that is ideally disaggregated by level of care (eg, outpatient/inpatient) and by type of public and private facility (eg, HC, public hospital, private hospital, etc).$^{29}$ Existing data sets in Cambodia such as the Health Management Information System do not provide this type of detailed usage information, making it necessary for this study to undertake a crosssectional household survey.

The Cambodian Health Equity and Financing (CHEF) household survey will involve the random selection of 5000 households across Cambodia, with 2000 households from urban areas and 3000 others from rural areas. This sample size will enable us to determine prevalence for characteristics with a $95 \%$ CI with a precision of $\pm 3 \%$. It will also allow us, with at least $80 \%$ power and a significance level of $5 \%$, to be able to detect differences of $5 \%$ for comparisons between urban and rural areas. In each selected household, one woman (the primary caregiver) or, in her absence, the male head will be interviewed. The interviews will be guided by a structured e-questionnaire, which covers key areas including living standard measures, demographic and socioeconomic data, health service use, satisfaction rating, quality of care and healthcare payments. Electronic data collection involving the use of laptops by enumerators will be used. The e-questionnaire will be designed using the NOVA Research Company's Questionnaire Development System (QDS) V.3.0 and administered with the computer-assisted personal interview program. A questionnaire previously used by this team in other Asia-Pacific countries will be adapted for use in Cambodia. $^{35}$ The questionnaire will be piloted among households from different socioeconomic backgrounds. Enumerators will undertake a 3-day training session in procedures for the household survey and be monitored by experienced supervisors in the field. The questionnaire and all related training materials will be made available here: https://sphcm.med.unsw.edu.au/project/ system-wide-analysis-health-financing-equity-cambodia.

Socioeconomic information, to enable the ranking of households by their living standards and for the assessment of ATP for healthcare, will be collected in the CHEF household survey.

\section{Financing incidence analysis}

FIA, also known as progressivity analysis, compares the distribution of the burden of healthcare payments with the distribution of overall economic resources. A health financing system is deemed progressive (regressive) relative to ATP if the rich contribute a relatively higher (lower) proportion of their income to healthcare financing than the poor. Payments to healthcare financing in Cambodia are primarily through taxes, direct outof-pocket payments, donor funding and voluntary health insurance. Taxes considered in this study include direct taxes (personal income tax and corporate tax) and indirect taxes (value added taxes, custom duty and withholding tax).

FIA comprises two stages of computation: (1) the progressivity of each type of healthcare payment; and (2) the overall progressivity of the healthcare system. To calculate the progressivity of each payment mechanism, payments made by households will be estimated as a percentage of total household expenditure and then triangulated with actual revenue for each revenue source from the Cambodian Ministry of Economy and Finance. Progressivity of the health system as a whole is calculated by weighting the progressivity of the different health financing sources by their relative contribution to total health funding. ${ }^{2} 28$

Progressivity of healthcare spending will be illustrated using the Lorenz and concentration curves. ${ }^{28} 33$ The Lorenz curve is a graphical representation of the cumulative distribution of ATP while the concentration curve plots the cumulative distribution of healthcare payments. The concentration index is twice the area between the concentration curve and line of equality. The concentration index ranges from -1.0 (entire financial burden is concentrated in the hands of the poorest person) to +1.0 (entire financial burden is concentrated in the hands of the richest person).

The relative progressivity of each source of healthcare revenue will also be assessed using the Kakwani index, ${ }^{36}$ a measure of inequality widely used in public finance including the assessment of equity in health systems financing. ${ }^{2} 28 \quad 33 \quad 37 \quad 38$ The Kakwani index, defined as twice the area between the concentration curve of health payments and the Lorenz curve, will be calculated as follows:

$$
\pi \mathrm{K}=\mathrm{C}-\mathrm{G}
$$

Where $\mathrm{C}$ is the health payment concentration index and $\mathrm{G}$ is the Gini coefficient of household income or expenditure. The value of the Kakwani index $(\pi \mathrm{K})$ ranges from -2.0 to +1.0. A negative index value indicates that healthcare payments are pro-rich (regressive) and that the concentration curve lies inside the Lorenz curve. In contrast, a positive value indicates the progressivity, and its concentration curve lies outside the Lorenz curve. To calculate overall progressivity of the health system, a weighted average of the Kakwani indices of the individual payment mechanisms will be derived, where the weights are the shares of total revenues coming from each source.

The construction of the ATP or socioeconomic measure in this study will be based on reported 
household consumption expenditures including food, housing and other household expenditures derived from the CSES data set. This measure, which has been applied in similar studies, ${ }^{2}{ }^{39-42}$ also takes into consideration consumption from sources other than purchases from the market (eg, subsistence agriculture products). Consumption expenditure is generally recognised as being more stable, reliable and easier to obtain than income. ${ }^{40}$ The pros and cons of different measures of ATP are discussed in detail elsewhere. ${ }^{40}$

Household estimates of aggregate expenditure will be adjusted to reflect household size and composition. ${ }^{2} 27$ Per adult equivalent household consumption will be calculated using the formula:

$$
\mathrm{AE}^{\mathrm{i}}=(\mathrm{Ai}+\alpha \mathrm{K})^{\theta}
$$

Where $\mathrm{A}$ is the number of adults in the household, $\mathrm{K}$ is the number of children $(0-14), \alpha$ is the 'cost of children' (given a value of 0.5 in this study) and $\theta$ determines the degree of economies of scale. ${ }^{39}$ The population will then be ranked by socioeconomic status and grouped into quintiles of equal size.

Tests of dominance will be performed to ascertain which payment mechanism is statistically progressive or regressive. ${ }^{43}$ A multiple comparison approach and 19 comparison points at $5 \%$ significance level will be used for the dominance tests as proposed by O'Donnell et $a l^{44}$ Sensitivity analysis will be used to assess how the results of the FIA differ under different assumptions and test whether any difference is statistically significant. ${ }^{44}$ For example, household income from the 2014 CSES will be explored as an alternative measure of socioeconomic status in the sensitivity analysis. Analyses will be performed using the Stata Statistical Software Package and the World Bank's ADePT Software Platform for Automated Economic Analysis. ${ }^{45}$

\section{Benefit incidence analysis}

BIA will be used to assess the distribution of healthcare benefits for public and private providers across socioeconomic groups and according to need for care. Specifically, we will analyse benefit incidence for inpatient, outpatient and preventive healthcare by level of care (ie, primary, hospital and referral level) and ownership of facilities (public, private for-profit, faithbased). We will use self-assessed health as a measure of need. ${ }^{27} 284042$

Usage rates for each category of health service will be multiplied by the unit cost of that service to estimate monetary benefits. ${ }^{27}$ For the government subsidy, out-of-pocket payments by service users will be subtracted from total benefits. ${ }^{27}$ To ascertain whether a benefit distribution for a given provider is pro-rich or pro-poor, we will construct bar charts indicating the relative share of total benefits received by each quintile. If the poorest members of the population receive a higher share of healthcare benefits compared with the rich, the system is deemed pro-poor. ${ }^{28}$ Further, we will compare the distribution of benefits, depicted by the concentration curve, against the $45^{\circ}$ line of perfect equality. If the concentration curve lies above (below) the $45^{\circ}$ line, the distribution is pro-poor (pro-rich).

Mathematically, benefit incidence is estimated by the following formula:

$$
\mathrm{X}_{\mathrm{j}}=\stackrel{\circ}{a_{\mathrm{i}}} \mathrm{U}_{\mathrm{ij}}\left(\mathrm{S}_{\mathrm{i}} / \mathrm{U}_{\mathrm{i}}\right)=\stackrel{\circ}{a_{\mathrm{i}}}\left(\mathrm{U}_{\mathrm{ij}} / \mathrm{U}_{\mathrm{i}}\right) \mathrm{S}_{\mathrm{i}}=\stackrel{\circ}{a_{\mathrm{i}}} \mathrm{e}_{\mathrm{ij}} \mathrm{S}_{\mathrm{i}}
$$

where $\mathrm{j}=$ sector-specific subsidy enjoyed by group $\mathrm{j}$; Uij=usage of service $i$ by group $j$; $U i=$ usage of service $i$ by all groups combined; $\mathrm{Si}=$ government net expenditure on service $\mathrm{i}$; and e $\mathrm{ij}=$ group $\mathrm{j}$ 's share of usage of service I. ${ }^{46}$

Equity implies that healthcare benefits are distributed according to healthcare need. ${ }^{29}$ Within the CHEF household survey, the household head will be asked to rank their health status on a scale of 1 to 3: good (rarely gets ill), fair (occasionally gets ill), bad (chronically and/or frequently ill). Those who ranked themselves to be either in poor or very poor health are considered to be in higher need of healthcare.

The sensitivity of the BIA results will be tested under three different assumptions: the constant unit cost assumption, which treats the sum of individual fees and government subsidies as constant; the constant unit subsidy assumption, which allocates the same subsidy to each unit of service used irrespective of the fees paid; and the proportional unit cost assumption, which makes the cost of care proportional to the fees paid. ${ }^{47}$ As for the FIA, analyses will be performed using the Stata Statistical Software Package and the World Bank's ADePT Software. ${ }^{45}$

The quality of health services and its impact on benefits received will also be explored in this study. Generally, quality services are based on evidence of what interventions are most effective and are provided in a technically competent way. ${ }^{6}$ It also extends to professional and empathic interpersonal engagements between providers and patients. ${ }^{6}$ Information on quality variation will be gathered in this study through focus group discussions with users and healthcare providers (see 'phase 2' below). These results will be reported separately to complement the quantitative results. In addition, we will seek to develop 'weightings' to be applied to health services in different districts (ie, rural and urban) to reflect, for example, how well staffed they are. ${ }^{48}$ Data required to develop such weightings will be obtained from secondary sources including the Health Sector Strategic Plan 2008-2015. ${ }^{9}$ This would be a first step in recognising variation in the quality of health services provided to different groups of users.

Phase 2: factors influencing equity in the delivery and payment of healthcare

Qualitative methods can be a powerful tool to aid understanding, provide explanations and explore in-depth the 
complexity of socioeconomic variables and perceptions underlying findings from quantitative surveys in health economics. ${ }^{49}{ }^{50}$ Qualitative methods have, for example, been used alongside financing and benefit incidence analyses to explore the factors that influence the burden of healthcare spending and distribution of healthcare benefits/use. ${ }^{49}$ Such methods have also been applied to understand the factors influencing the implementation of different financing reforms including community health insurance schemes, vouchers and HEFs in Cambodia and other LMICs. ${ }^{18} 5152$ For this study, topics that have strategic importance for equity, economic burden and distribution of benefits across socioeconomic groups will be selected after review of the quantitative findings and the identification of gaps in the literature on healthcare financing in Cambodia. The key domains for qualitative analysis are likely to include access within the community to information about health services and entitlements, including insurance schemes and user fee exemptions for the poor; patients' perceptions about the quality of public and private health services; physical access to health providers including access to preventive care and travelling time; the costs of seeking healthcare; economic behaviour and borrowing practices of patients and their families; and the availability of private services inside and outside the country. These domains will be considered across the spectrum of Cambodian society, from the rich and middle class to the most vulnerable population groups.

\section{Data sources and sampling}

IDIs will be conducted with two categories of participants: (1) community/household members and (2) key informants who can discuss relevant health service and policy issues such as policymakers, health professionals, senior staff at local non-government organisations and international organisations. Participants at the household level will be selected across socioeconomic groups as identified in the quantitative component of the study (eg, urban middle class, urban poor, rural populations). Sampling will continue until data saturation is achieved but it is estimated that 15-20 IDIs will be required per population group. Interviews will be conducted in Khmer, taped and subsequently translated into English. Given that decisions about health service usage and spending are made in a 'social context', a series of FGDs will also be conducted. Approximately 20 FGDs will be conducted at the community level and will be segmented by location (rural/urban) and by gender (male/ female) to encourage effective and open discussion. Each FGD will have about 6-8 adult household members who have not already participated in an IDI. Different approaches such as the use of warm-up questions, a non-threatening environment and a clear explanation of the goals of the discussion will be used to build trust in the moderator and the process. Two local facilitators and four interviewers who speak Khmer will be trained by an experienced qualitative researcher
(ML) to support the FGDs and IDIs. The qualitative data will be coded and analysed using a thematic content analysis approach based on a framework developed through an iterative process to harness the full explanatory and interpretive potential of the qualitative data set. ${ }^{53}{ }^{54}$ Short summaries of the IDIs and FGDs will be compiled and emerging themes will be used to guide data coding, using QSR NVivo V.11. Independent coding will be carried out by the research team and codes will be repeatedly reviewed for validation and reliability, and compared with the initial data summaries.

\section{Phase 3: merging and interpretation of results}

The qualitative and quantitative strands of the study will first be interpreted and presented separately. Then they will be merged to provide a more complete understanding of equity in health systems financing, with particular attention to potential challenges (and opportunities) that may result from divergences in theoretical foundations, methods, generalisability and presentational norms across disciplinary perspectives. ${ }^{55}$ After careful evaluations of these issues, different integration methods will be developed and used to promote understanding across different target audiences (see 'target audiences and involvement strategies' section below). These may include narratives where qualitative and quantitative findings are described together in a report on a theme-by-theme basis and joint displays for organising the related data in figures, tables and graphs. ${ }^{55}{ }^{56}$ Where appropriate, the qualitative results will also be mapped to the findings from the financing and benefit incidence analyses-for example, if the BIA were to reveal a prorich distribution of benefits resulting from limited access to higher level facilities among poor and rural populations, then this would be complemented by qualitative information on the different types of barriers in accessing healthcare and their relative importance from a consumer and provider perspective.

\section{Data management and quality assurance}

All research materials and data from this study will be held and preserved in accordance with the University of New South Wales' (UNSW) Research Data management guidelines: http://www.gs. unsw.edu.au/policy/ documents/researchdataproc.pdf. Quality assurance procedures will be built into the data management system and implemented alongside other data management activities to ensure timely detection and resolution of errors in the data. A central project database that is password protected will be established using the UNSW research data portal. This will be the ultimate home of the data and will be established in advance of data collection. Access to the database will be given only to members of the study team. The use of the e-data collection method means that data can be transferred directly from the field to the project central database immediately after collection. There will be a dedicated staff member to receive all data and 
prepare it for analysis. The data will be archived using the UNSW long-term data archiving system.

\section{Target audiences and involvement strategies}

This study will involve policymakers through local workshops and other means using locally appropriate approaches including targeting annual health review and strategic health planning meetings. The approach taken can be characterised as evidence of co-production - a process of conducting research in collaboration with its end users. This approach has been shown to promote research findings that are relevant to decision makers and more likely to be taken up in practice. ${ }^{57-59}$ Two team members are situated in the Department of Planning and Health Information that houses the Bureau of Health Financing in the Cambodian Ministry of Health and will be in an ideal position to feed the results of this project into key decision-making processes. To reach academic audiences, results will be published in relevant scholarly journals and presented to appropriate national, regional and international audiences, policymakers and stakeholders at high-profile international meetings including the Global Symposium on Health Systems Research and the annual International Health Economics Association Congress. Results and tools (surveys and training materials) arising from this project will be shared with students trained at each of the participating universities and other academic institutions in the Asia-Pacific region. These future health practitioners will benefit from the lessons of the project through teaching material developed by members of this project. Finally, information about this project will be disseminated to members of the public, researchers and study stakeholders through an interactive website, podcasts and webinars.

\section{Ethical considerations}

Ethical clearance for the quantitative component of the study has been obtained from the National Ethics Committee for Health Research in Cambodia (REF: 362 NECHR) and the University of New South Wales (REF: HC1543). Ethical approval for the qualitative part of the study will be sought once the quantitative component is completed.

\footnotetext{
Author affiliations

${ }^{1}$ Department of Public Health \& Community Medicine, University of New South Wales, Sydney, New South Wales, Australia

${ }^{2}$ Department of Global Health and Development, London School of Hygiene and Tropical Medicine, London, UK

${ }^{3}$ National Institute of Public Health, Phnom Penh, Cambodia

${ }^{4}$ Khon Kaen University, Khon Kaen, Thailand

${ }^{5}$ Ministry of Public Health International Health Policy Program (IHPP), Thailand

${ }^{6}$ Social Health Protection Programme, Deutsche Gesellschaft für Internationale Zusammenarbeit (GIZ), Phnom Penh, Cambodia

${ }^{7}$ Faculty of Health, University of Technology Sydney Sydney, New South Wales, Australia

${ }^{8}$ George Institute for Global Health, Sydney, New South Wales, Australia
}

Handling editor Seye Abimbola

Contributors All authors contributed to the design of the study. AA, AH, SL and PI led the design of the quantitative component of the study. ML, PI and BJ led the design of the qualitative component of the study. VW and SJ led the drafting of the manuscript, which was reviewed and commented on by all authors.

Funding Australian Research Council. Grant number (DP150101321).

Competing interests None declared.

Ethics approval National Ethics Committee for Health Research in Cambodia (REF: 362 NECHR) and the University of New South Wales (REF: HC1543).

Provenance and peer review Not commissioned; externally peer reviewed.

Data sharing statement No additional data are available.

Open Access This is an Open Access article distributed in accordance with the Creative Commons Attribution Non Commercial (CC BY-NC 4.0) license, which permits others to distribute, remix, adapt, build upon this work noncommercially, and license their derivative works on different terms, provided the original work is properly cited and the use is non-commercial. See: http:// creativecommons.org/licenses/by-nc/4.0/

\section{REFERENCES}

1. Lagomarsino G, Garabrant A, Adyas A, et al. Moving towards universal health coverage: health insurance reforms in nine developing countries in Africa and Asia. Lancet 2012;380:933-43.

2. Mills A, Ataguba JE, Akazili J, et al. Equity in financing and use of health care in Ghana, South Africa, and Tanzania: implications for paths to universal coverage. Lancet 2012;380:126-33.

3. Victora C, Saracci R, Olsen J. Universal health coverage and the post-2015 agenda. Lancet 2013;381:60581-4.

4. WHA. Sustainable health financing structures and universal coverage: 64th World Health Assembly agenda item 13.4. 2011. http://apps.who.int/gb/ebwha/pdf_fi les/WHA64/A64_R9-en.pdf (accessed 30 Aug 2011).

5. World Health Organisation. Health systems financing: the path to universal coverage. Geneva: WHO, 2010. http://apps.who.int/iris/ bitstream/10665/44371/1/9789241564021_eng.pdf

6. McIntyre D, Kutzin J. Health financing country diagnostic: a foundation for national strategy development. World Health Organization, 2016. http://apps.who.int/iris/handle/10665/204283

7. Kutzin J. Health financing for universal coverage and health system performance: concepts and implications for policy. Bull World Health Organ 2013;91:602-11.

8. Fryatt R, Mills A. Taskforce on Innovative International Financing for Health Systems: showing the way forward. Bull World Health Organ 2012;88:476-7.

9. Ministry of Health. Strategic Health Plan 2008-2015. Department of planning and health information. Phnom Penh: Ministry of Health, 2008. http://www.wpro.who.int/health_services/cambodia nationalhealthplan.pdf

10. Annear PL. Combining health equity funds and community-based health insurance. Health Policy and Health Financing Knowledge Hub. Policy Brief 4. 2012. http://ni.unimelb.edu.au/_data/assets/ pdf_file/0009/623970/PB4_-_Cambodia_and_Laos.pdf

11. Sobrado C, Neak S, Ly S, et al. Where have all the poor gone? Cambodia poverty assessment 2013. A World Bank country study. Washington DC: The World Bank Group, 2013. http://documents. worldbank.org/curated/en/824341468017405577/

Where-have-all-the-poor-gone-Cambodia-poverty-assessment-2013

12. Annear P, Nachtnebel M, Jacobs B. eds. The Kingdom of Cambodia health system review, Health Systems in Transition. 2015;5:2. http:// iris.wpro.who.int/bitstream/handle/10665.1/11356/9789290616917_ eng.pdf.

13. Kwon S, Meng QY, Tangcharoensathien V, et al. Direct household payments for health services in Asia and the Pacific. Asia Pacific Observatory on Health Systems and Policies. Manila: World Health Organization, Regional Office for the Western Pacific, 2012. http:// www.wpro.who.int/asia_pacific_observatory/resources/policy_briefs/ household_payments_health_services_asia_pacific.pdf

14. National Institute of Statistics. Directorate General for Health, and ICF International. Cambodian Demographic and Health Survey, 2014. https://dhsprogram.com/pubs/pdf/FR312/FR312.pdf

15. Ir $\mathrm{P}$, Korachais $\mathrm{C}$, Chheng $\mathrm{K}$, et al. Boosting facility deliveries with results-based financing: a mixed-methods evaluation of the 
government midwifery incentive scheme in Cambodia. BMC Pregnancy Childbirth 2015;15:170.

16. Van de Poel E, Flores G, Ir P, et al. Impact of performance-based financing in a low-resource setting: a decade of experience in Cambodia. Health Econ 2016;25:688-705.

17. Van de Poel E, Flores G, Ir P, et al. Can vouchers deliver? An evaluation of subsidies for maternal health care in Cambodia. Bull World Health Organ 2014;92:331-9.

18. Ir $\mathrm{P}$, Horemans $\mathrm{D}$, Souk $\mathrm{N}$, et al. Using targeted vouchers and health equity funds to improve access to skilled birth attendants for poor women: a case study in three rural health districts in Cambodia. BMC Pregnancy Childbirth 2010;10:1

19. Annear PL, Khim K, Ir P, et al. National coverage and health service utilization by Health Equity Fund members, 2004-2015. ADRA Research Report. 2016.

20. Annear P. A comprehensive review of the literature on health equity funds in Cambodia 2001-2010 and annotated bibliography. Nossal Institute for Global Health, The University of Melbourne. 2010. http:// healthmarketinnovations.org/sites/default/files/A\%20comprehensive \%20review\%20of\%20the\%20literature\%20on.pdf

21. Flores $\mathrm{G}$, Ir P, Men $\mathrm{CR}$, et al. Financial protection of patients through compensation of providers: the impact of Health Equity Funds in Cambodia. J Health Econ 2013;32:1180-93.

22. Gottret $\mathrm{P}$, Schieber $\mathrm{G}$. Health financing revisited. A practitioner's guide. The International Bank for Reconstruction and Development. The World Bank, 2006. http://siteresources.worldbank.org/INTHSD/ Resources/topics/Health-Financing/HFRFull.pdf

23. Schieber G, Maeda A. A Curmudgeon's guide to financing health in developing countries. In: Schieber G, ed. Innovations in health care financing. Discussion Paper 365, World Bank. Washington, DC: 1997. http://www1.worldbank.org/publicsector/pe/PEAMMarch2005/ multi_page.pdf.

24. United Nations. World Statistics Pocketbook. United Nations Statistics Division. 2016. http://data.un.org/CountryProfile.aspx? crName $=$ Cambodia

25. World Health Organization and Ministry of Health. Cambodia: Health Service Delivery Profile Cambodia, 2012. http://www.wpro.who.int/ health_services/service_delivery_profile_cambodia.pdf

26. World Bank. Cambodia's rural health markets and the quality of care. Health, nutrition, and population (HNP) knowledge brief. Washington DC: World Bank Group, 2014. http://documents. worldbank.org/curated/en/514181468213569828/

Cambodias-rural-health-markets-and-the-quality-of-care

27. O'Donnell O, van Doorslaer E, Wagstaff A, et al. Analyzing health equity using household survey data: a guide to techniques and their implementation. Washington DC: World Bank, 2008 http:// siteresources.worldbank.org/INTPAH/Resources/Publications/ 459843-1195594469249/HealthEquityFINAL.pdf

28. Mtei G, Makawia S, Ally M, et al. Who pays and who benefits from health care? An assessment of equity in health care financing and benefit distribution in Tanzania. Health Policy Plan 2012;27(Suppl 1):i23-34

29. Mclntyre D, Ataguba JE. How to do (or not to do) a benefit incidence analysis. Health Policy Plan 2011;26:174-82.

30. Wiseman V, Asante A, Price J, et al. Ten best resources for conducting financing and benefit incidence analysis in resource-poor settings. Health Policy Plan 2015;30:1053-8.

31. Ministry of Health. Estimating health expenditure in Cambodia: National Health Accounts Report, 2013-2014. Phomn Penh, Cambodia: Bureau of Health Economics and Financing, Department of Planning and Health Information, 2015.

32. Cambodia National Institute of Statistics. Cambodia Socio-Economic Survey (CSES) 2014, Ministry of Planning. Phnom Penh, Cambodia 2015. http://www.ilearnincambodia.net/uploads/3/1/0/9/31096741/ cses_2014_report.pdf.

33. Akazili J, Garshong B, Aikins M, et al. Progressivity of health care financing and incidence of service benefits in Ghana. Health Policy Plan 2012;27(suppl 1): i13-22.

34. Martin A. Cambodia hospital costing and financial management study Final Report 2012, Phomn Penh. Department of Planning and Health Information (DPHI), Cambodia Ministry of Health, 2012.
35. Asante AD, Price J, Hayen A, et al. Assessment of equity in healthcare financing in Fiji and Timor-Leste: a study protocol. BMJ Open 2014;24:e006806.

36. Kakwani N. Measurement of tax progressivity: an international comparison. Econ J 1977;87:71-80.

37. Cissé B, Luchinia S, Moatti JP. Progressivity and horizontal equity in health care finance and delivery: what about Africa? Health Policy 2007;80:51-68

38. Asante A, Price J, Hayen A, et al. Equity in health care financing in low-and middle-income countries: a systematic review of evidence from studies using benefit and financing incidence analyses. PLOS ONE 2016;11:e0152866.

39. Ataguba JE, Mclntyre D. Paying for and receiving benefits from health services in South Africa: is the health system equitable? Health Policy Plan 2012;27(Suppl 1):i35-45.

40. Kwesiga B, Ataguba JE, Abewe C, et al. Who pays for and who benefits from health care services in Uganda? BMC Health Serv Res 2015;15:44.

41. Akazili J, Gyapong J, Mclntyre D. Who pays for health care in Ghana? Int J Equity Health 2011;10:26.

42. Chuma J, Maina T, Ataguba J. Does the distribution of health care benefits in Kenya meet the principles of universal coverage? BMC Public Health 2012;12:20.

43. Dardanoni V, Forcina A. Inference for Lorenz curve orderings. Econometrics J 1999;2:49-75

44. O'Donnell O, Van Doorslaer E, Rannan-Eliya RP, et al. The incidence of public spending on healthcare: comparative evidence from Asia. World Bank Econ Rev 2007;21: 93-123.

45. Lokshin M, Radyakin S, Sajaia Z, et al. A DepT Users Guide. Version 5. Washington DC: The World Bank, 2013. http:// siteresources.worldbank.org/EXTADEPT/Resources/adept_ug.pdf.

46. Deaton A. The analysis of household surveys. Baltimore, MD: Johns Hopkins University Press, 1997.

47. Wagstaff A. Benefit-incidence analysis: are government health expenditures more pro-rich than we think? Health Econ 2012;21:351-66.

48. Davoodi H, Tiongson ER, Asawanuchit SS. How useful are benefit incidence analyses of public education and health spending?. IMF Working Paper 2003, WP/03/227. http://citeseerx.ist.psu.edu/ viewdoc/download?doi=10.1.1.558.4225\& rep=rep1\&type=pdf

49. Macha J, Harris B, Garshong B, et al. Factors influencing the burden of health care financing and the distribution of health care benefits in Ghana, Tanzania and South Africa. Health Policy Plan 2012;27:46-i54.

50. Limwattananon S, Tangcharoensathien V, Tisayaticom K, et al. Why has the universal coverage scheme in Thailand achieved a pro-poor public subsidy for health care? BMC Public Health 2012;12:S6.

51. Hardeman W, Van Damme W, Van Pelt M, et al. Access to health care for all? User fees plus a Health Equity Fund in Sotnikum, Cambodia. Health Policy Plan 2004;19:22-32.

52. Kamuzora P, Gilson L. Factors influencing implementation of the Community Health Fund in Tanzania. Health Policy Plan 2007;22:95-102.

53. Guest G, MacQueen KM, Namey EE. Applied thematic analysis. Thousand Oaks, CA: Sage, 2012.

54. Coast J, McDonald R, Baker R. Issues arising from the use of qualitative methods in health economics. J Health Serv Res Policy 2004;9:171-6.

55. Fetters MD, Curry LA, Creswell JW. Achieving integration in mixed methods designs-principles and practices. Health Serv Res 2013;48(Pt 2):2134-56

56. Craig $P$, Dieppe $P$, Macintyre $S$, et al. Developing and evaluating complex interventions: the new Medical Research Council guidance. BMJ 2008;337:a1655

57. Jasanoff S. States of knowledge: the co-production of science and the social order. London: Routledge, 2004

58. Boyle D, Slay J, Stephens L. Public services inside out: Putting co-production into practice. London: NESTA, 2010.

59. Jackson CL, Greenhalgh T. Co-creation: a new approach to optimising research impact? Med J Aust 2015;203:283-4. 